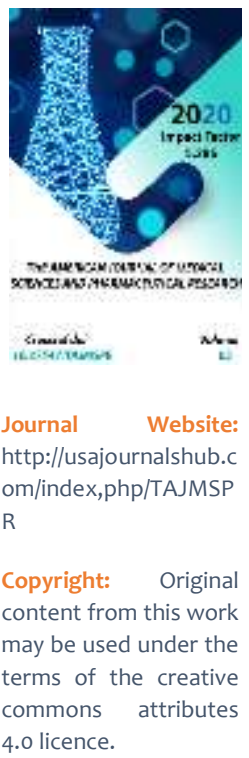

\section{Results Of Treatment Of Acute Diffuse Purulent Peritonitis Using Laparostomy}

\author{
S. A. Ruziboev \\ Samarkand State Medical Institute, Samarkand Branch Of The Republican Scientific Center \\ For Emergency Medical Care. Uzbekistan
}

\author{
A. A. Avazov \\ Samarkand State Medical Institute, Samarkand Branch Of The Republican Scientific Center \\ For Emergency Medical Care. Uzbekistan \\ Sh. Kh. Sattarov \\ Samarkand State Medical Institute, Samarkand Branch Of The Republican Scientific Center \\ For Emergency Medical Care. Uzbekistan \\ A. N. Elmuradov \\ Samarkand State Medical Institute, Samarkand Branch Of The Republican Scientific Center \\ For Emergency Medical Care. Uzbekistan
}

\title{
ABSTRACT
}

Currently, despite significant achievements in the field of surgery, anesthesiology and resuscitation, the results of treatment of patients with advanced purulent peritonitis remain one of the most intractable problems, almost every sixth patient with acute surgical diseases and injuries of the abdominal cavity is admitted to medical institutions with peritonitis [1,3] Common peritonitis in 17-29\% complicates the course of most acute surgical diseases and is the main cause of deaths in surgical hospitals [3,7]. Lethality in advanced peritonitis remains extremely high and reaches $20-39 \%[1,2,4,5]$. In recent decades, great importance has been attached to recording intra-abdominal pressure in purulent pathology of the abdominal cavity. It was found that intra-abdominal hypertension occurs in every third patient with acute surgical pathology and negatively affects the functioning of all organs and systems of the body $[1,6,8]$. Pathological changes that occur with acute and excessive increase in intra-abdominal pressure (IAP) are manifestations of abdominal compartment syndrome (ACS) with disorders of the cardiovascular system; urinary disorders, disorders of perfusion of internal organs and the development of intestinal ischemia, which contributes to bacterial translocation and endogenous infection $[2,7,8]$. Ischemic blood flow disorders of the splanchnic zone are fraught with the development of bacterial translocation and the development of systemic inflammatory response syndrome and multiple organ failure (PON). Unsatisfactoriness with such results gave rise to a fundamentally different approach to the surgical treatment of common forms of peritonitis-the introduction of an open abdominal management method based on the ideas of I. Mikulich (1881), JeanLouis Faure (1928), N. S. Makoch (1984) and D. Steinberg (1979). 


\section{KEYWORDS}

Relaparotomy, laparostomy, peritonitis, surgery

\section{INTRODUCTION}

\section{Objective}

Clinical assessment of the place and significance of relaparotomy - "on demand" in the treatment of spilled purulent peritonitis, by improving and implementing more effective methods of diagnosis and treatment.

\section{MATERIAL AND METHODS}

To compare the effectiveness of laparostomy, we analyzed the results of treatment of 46 patients in the Samarkand branch of the rscemp in the period from 2012 to 2019, who underwent relaparotomy "on demand" and 68 patients who included the laparostomy method with program rehabilitation of the abdominal cavity in the complex of treatment measures. The patients were aged from 16 to 75 years (average 56.6 \pm 3.7 ). There were 76 men (66.7\%) and 38 women (33.3\%) among the patients.

All patients were diagnosed with terminal peritonitis. The duration of peritonitis in the patients we observed was, on average, 3.5 days, and the value of the Mannheim peritonitis index was in the range of 25-47 points.

The main cause of spilled purulent peritonitis in the observed patients was acute destructive appendicitis (table 1). 
The American Journal of Medical Sciences and Pharmaceutical Research (ISSN - 2689-1026)

Published: November 28, 2020 | Pages: 66-71

Doi: https://doi.org/10.37547/TAJMSPR/Volume02Issue11-12

\begin{tabular}{|c|c|c|c|c|}
\hline \multirow{3}{*}{ Reasons } & \multicolumn{4}{|c|}{ Number of patients } \\
\hline & \multicolumn{2}{|c|}{ study group $\quad(n=68)$} & \multicolumn{2}{|c|}{ control group $(n=46)$} \\
\hline & abs. & $\%$ & abs. & $\%$ \\
\hline Acute destructive appendicitis & 18 & 26,5 & 14 & 30,4 \\
\hline $\begin{array}{l}\text { Postoperative intra-abdominal } \\
\text { abscesses }\end{array}$ & 11 & 16,2 & 7 & 15,2 \\
\hline $\begin{array}{l}\text { Peritonitis on the background of } \\
\text { strangulation intestinal obstruction }\end{array}$ & 10 & 14,7 & 6 & 13 \\
\hline $\begin{array}{l}\text { The inconsistency of seams } \\
\text { intestinal anastomosis }\end{array}$ & 11 & 16,2 & 7 & 15,2 \\
\hline $\begin{array}{l}\text { Perforation of hollow organs: } \\
\text { - perforation of the duodenal ulcer } \\
\text { and stomach }\end{array}$ & 3 & 4,4 & - & - \\
\hline & 5 & 7,4 & 5 & 10,9 \\
\hline & 4 & 5 & 3 & 6,5 \\
\hline $\begin{array}{l}\text { Traumatic damage to the } \\
\text { abdominal organs }\end{array}$ & 3 & 4,4 & 2 & 4,3 \\
\hline Acute cholecystitis & 3 & 4,4 & 2 & 4,3 \\
\hline
\end{tabular}

The duration of peritonitis in the control group was, on average, 3.3 days. Patients of both groups were comparable in age, gender, severity of the main and concomitant pathology, and the nature of surgical interventions performed.

The main elements of laparostomy are: a wide revision of the abdominal organs, elimination of the source of infection (emptying of pus accumulations, excision of necrotic tissues, resection of intestinal segments bearing fistulas or failed anastomoses, ileo - or colostomy), abundant washing with antiseptic solutions, drainage of the abdominal cavity, intestinal loops are closed with an omentum, perforated films (nets) on top, 1-2 sutures on 
the skin (Fig.1,2), with daily bandages and repeated laparosanation every 48-72 hours.

Indications for laparotomy were:

- Common purulent or fecal peritonitis,

- The presence of multiple difficult-toremove purulent-fibrinous overlays on the peritoneum,

- Signs of anaerobic infection,

- Impossibility of simultaneous elimination of the source of peritonitis,
- The condition of a laparotomic wound that does not allow to close the defect of the anterior abdominal wall (total suppuration of the wound, phlegmon of the anterior abdominal wall),

- Developing abdominal abscesses,

- Questionable viability of part of the organ (in 21 patients with acute mesenteric circulatory disorders)

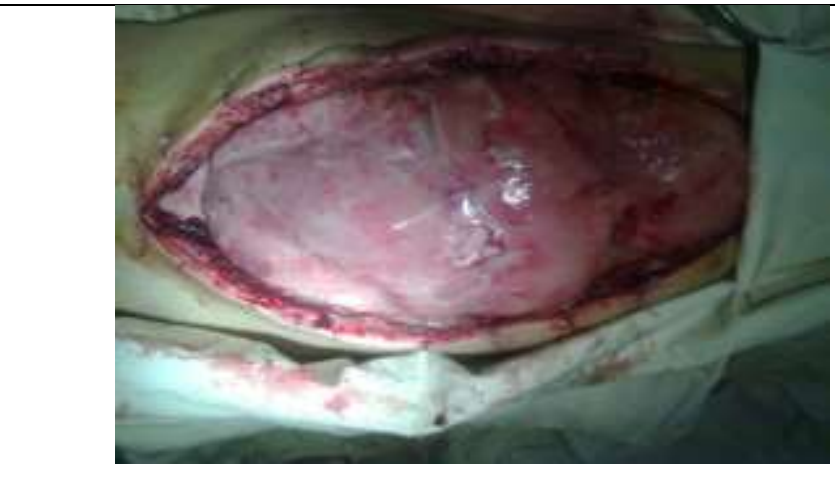

Fig.1 Covering the intestinal loops with a film coating.

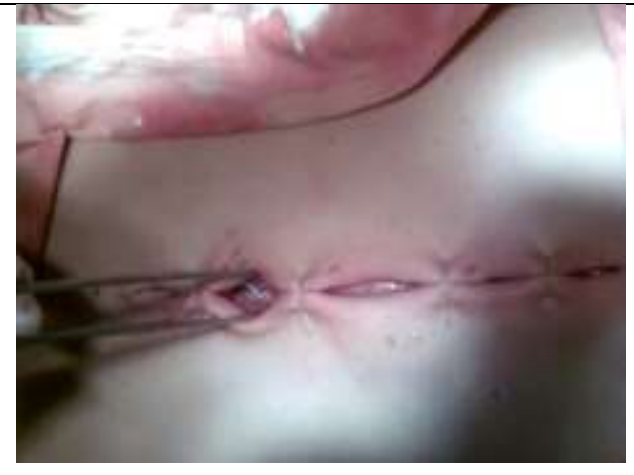

Fig. 2 Applying rare stitches to the skin.
Intra-abdominal pressure was measured by the Kron method for all patients at admission and then during surgical treatment. Indicators of intra-abdominal pressure ranged from 16.4 to $42 \mathrm{~cm}$ of water.

Research result. Management of patients in the control group $(n=46)$ provided for abdominal sanation on "demand", indications for the next sanation were set according to the clinical picture of the abdominal cavity and ultrasound data. Between abdominal sanation, the laparotomy wound was sutured with widereaching sutures through all layers of the anterior abdominal wall. In the main group $(n=68)$, the abdominal cavity was closed by applying a laparostomy, between abdominal sanation, the laparotomy wound was sutured with several skin wide-coverage sutures, decompression intubation of the small intestine with the introduction of $100-150 \mathrm{ml}$ of $0.25 \%$ novocaine solution into the mesentery root, and in the postoperative period, catheterization of the peridural space was used for 4-5 days. Laparostomy was applied in the presence of a large amount of exudate with a putrid smell, massive fibrinous overlays on the parietal peritoneum and intestinal loops, the likelihood of inter-intestinal abscesses and purulent process in the walls of the laparotomy wound. The terms of the next sanation were determined based on the hemogram readings, the leukocyte intoxication index, the state of the peritoneum and intestines, and intra- 
abdominal pressure indicators (using the Kron method). Microbiological examination was performed in both groups of patients. The growth of bacteria (surviving patients) was stopped after 3-5 redevelopments. The concentration of microbial bodies in $1 \mathrm{ml}$ before sanitation was (on average) 2, 6×108 CFU, and after 3-4 sanitation-3, 5X105 CFU.

The laparostomy method was used in 61 (89.7\%) patients immediately after the primary operation for General peritonitis and in 7 (10.3\%) patients after relaparotomy performed for complications of peritonitis on $3.3 \pm 0.4$ days.

The effectiveness of the treatment was controlled by the General condition of patients and changes in the dynamics of clinical and laboratory indicators of the activity of the inflammatory process in the body.

The moment for closing the abdominal cavity is considered appropriate when the temperature decreases to normal or subfebrile numbers, the number of white blood cells decreases to 10-12x109/l, the hydroionic balance and acidbase state normalize, the signs of organ or multi-organ dysfunction disappear, purulent exudation stops, and intestinal transit is restored.

This favorable course of the postoperative period was observed in 59 (86.8\%) patients. The abdominal cavity was closed after they have 3-4 of laparocele.

In $33(71.7 \%)$ patients in the control group, after some improvement following relaparotomy, symptoms of increasing abdominal sepsis reappeared. Repeated relaparotomies revealed the causes of their occurrence. New perforations of the ileum at the site of sutures applied during the first operation - in 3 patients (typhoid fever), progressive paralytic obstruction - 10 and fresh accumulations of pus in the intestinal and subdiaphragmal spaces - in 20 patients. The perforation has required a bowel resection and releaseme, obstruction eliminated by the imposition of an ileostomy, abscesses drained. Treatment of peritonitis in this group lasted longer than in the main group.

- The effectiveness of the treatment was controlled by the General condition of patients and changes in the dynamics of clinical and laboratory indicators of the activity of inflammatory processes in the body.

- The time intervals between re-audit and leprosarium and amounted to 24-48 hours.

- The time required for elimination of peritonitis with open abdominal management ranged from 6-8 days to 3 weeks, and the number of repeated sanations - up to 5 .

- All patients underwent nasointestinal intubation with the Miller-Abbott probe until distinct peristalsis appeared (4-5 days) and intra-abdominal pressure decreased to $15 \mathrm{mmHg}$ or lower.

Fatal outcome occurred in 16 (23.5\%) cases: with progressive peritonitis (9), due to sepsis and exhaustion with high intestinal fistulas (4), due to pileflebitis (3) with the formation of multiple liver abscesses and due to hepaticrenal failure.

Thus, the open method can improve the results of complex treatment of the most severe forms of peritonitis. 


\section{CONCLUSIONS}

1. Method of selecting operation is completed, the most severe forms of peritonitis with relaparotomy is laparotomy with programmable laparocentesis.

2. Laparotomy allows active and timely correction of abdominal complications, improves the results of treatment of patients.

3. In severe forms of widespread purulent peritonitis, with the development of intraabdominal hypertension syndrome, it is necessary to expand the indications for laparostomy, including using modern polymer materials for temporary closure of the abdominal cavity.

\section{REFERENCES}

1. Derbentseva T. V., Maskin C. C., Golbreich V. A. Program and emergency relaparotomies in the treatment of common peritonitis // Bulletin of the Volgograd state medical University. - 2012. - №4(44). -P. 105-107.

2. Kuevda E. V. Laparostomy in the treatment of common peritonitis // Bulletin of the Russian state medical University, 2011, no. 1, Pp. 359-360.

3. Kuevda E. V. Tactics of treatment of patients with advanced peritonitis taking into account the influence of intraabdominal hypertension // Collection of materials of the conference "postgraduate and doctoral readings: new age Challenges search for innovations". - Moscow, 2012. - P. 97-99.

4. Maskin C. C., Golbreich V. A., Lopasteisky D. S. Programmed and emergency relaparotomies for common peritonitis and intra-abdominal complications / / XI
Congress of surgeons of the Russian Federation: Mater. Congress's. - Volgograd: Publishing house of Vol.GMU, 2011. - P. 533534.

5. Maskin C. C., Derbentseva T. V., Karsanova N. M., etc. Results of programmed and emergency relaparotomy for advanced purulent peritonitis // Matera. city scientific and practical conference-Moscow, 2012. Pp. 74-75.

6. Savchenko Yu. P., Kuevda E. V., Golikov I. V. intra-abdominal hypertension Syndrome in the choice of surgical treatment of acute widespread peritonitis // Bulletin of experimental and clinical surgery, 2011, Vol. 4, No. 1, Pp. 148-151.

7. Timerbulatov V. M., Timerbulatov sh. V., Gareev R.N., etc. Prognostic value of criteria for intraabdominal hypertension syndrome in emergency abdominal surgery / / Infections in surgery. - 2010. - No. 4. - Pp. 4446.

8. Fayazov R. R., Timerbulatov sh. V., Gareevr. $N$. et al.Intraabdominal hypertension in emergency surgery / / Medical Bulletin of Bashkortostan. - 2008. - No. 5. - Pp. 64-67. 